CLINICAL STUDY

\title{
Thyroid hormone is a critical determinant of myocardial performance in patients with heart failure: potential therapeutic implications
}

\author{
Constantinos Pantos, Athanasios Dritsas ${ }^{1}$, Iordanis Mourouzis, Antonios Dimopoulos, Georgios Karatasakis ${ }^{1}$, \\ Georgios Athanassopoulos $^{1}$, Sofia Mavrogeni ${ }^{1}$, Athanasios Manginas ${ }^{1}$ and Dennis V Cokkinos ${ }^{1}$ \\ Department of Pharmacology, University of Athens, 75 Mikras Asias Avenue, 11527 Goudi, Athens, Greece and ${ }^{1} 1$ st Cardiology Department, Onassis \\ Cardiac Surgery Center, 356 Sygrou Avenue, 17674 Kallithea, Athens, Greece
}

(Correspondence should be addressed to C Pantos; Email: cpantos@cc.uoa.gr)

\begin{abstract}
Objective: Previous experimental studies have provided evidence showing that changes in thyroid hormone signaling correspond to alterations in myocardial function in animal models of heart failure. The present study further explores whether thyroid hormone alterations are correlated with the functional status of the myocardium in patients with heart failure.

Methods: In this study, 37 patients with mean ejection fraction (EF\%) of 26.2 (8.2) were included. Myocardial performance was assessed by echocardiography and cardiopulmonary exercise testing. Total tri-iodothyronine $\left(\mathrm{T}_{3}\right)$, thyroxine, and TSH levels were measured in plasma.

Results: Total $\mathrm{T}_{3}$ was strongly correlated with $V_{2} \max \left(r=0.78, P=2 \times 10^{-8}\right)$. Furthermore, multivariate analysis revealed that total $\mathrm{T}_{3}$ was an independent predictor of $V \mathrm{O}_{2 \max }(P=0.000005)$. A weaker but significant correlation was also found between total $\mathrm{T}_{3}$ and $\mathrm{EF} \%(r=0.56, P=0.0004)$, systolic $(r=0.43, P=0.009)$ and diastolic $(r=0.46, P=0.004)$ blood pressure.

Conclusions: changes in thyroid hormone were closely correlated to myocardial functional status in patients with heart failure. These data probably indicate a possible role of thyroid hormone in the pathophysiology of heart failure and confirm previous experimental reports.
\end{abstract}

European Journal of Endocrinology 157 515-520

\section{Introduction}

Although several genes encoding the expression of important regulatory and structural proteins in the myocardium are thyroid hormone responsive $(1,2)$, the role of thyroid hormone in the pathophysiology of heart failure has not been adequately explored. Initial studies demonstrated that reduction in plasma triiodothyronine $\left(\mathrm{T}_{3}\right)$ without significant changes in thyroxine $\left(\mathrm{T}_{4}\right)$ can occur in patients with cardiac or non-cardiac illnesses $(1,3)$. This is known as the low $\mathrm{T}_{3}$ state' and has been considered as an adaptive response, which needs no treatment (4). However, it is now recognized that low total $\mathrm{T}_{3}$ levels in plasma may be an independent factor for mortality in patients with heart failure $(5,6)$, indicating that thyroid hormone probably has an important role in the pathophysiology of heart failure. Such a possibility is further supported by recent experimental studies which clearly demonstrate that changes in thyroid hormone-thyroid nuclear receptor axis occur in the failing myocardium and correlate to cardiac dysfunction (7-10). Based on this evidence, the present study has further explored whether thyroid hormone can be correlated to functional myocardial status in patients with dilated cardiomyopathy of ischemic or non-ischemic origin.

\section{Methods}

\section{Patients and measurements}

Thirty-seven consecutive patients with mean left ventricular ejection fraction (EF) of 26.2 (8.2) were studied; $25(67.6 \%)$ had non-ischemic dilated cardiomyopathy and $12(32.4 \%)$ had post-ischemic dilated cardiomyopathy. The diagnosis of the dilated cardiomyopathy was established in all patients at least 6 months prior to the study. All patients were in stable clinical condition (no change in clinical symptoms, no hospitalization and i.v. inotropic treatment for 3 weeks prior to hospital admission and during the study) and on conventional medical treatment for heart failure with diuretics, angiotensin-converting enzyme inhibitors, and $\beta$-blockers. Treatment was unchanged for at least 2 months prior to admission and remained unchanged during the study. All patients were admitted to the hospital for scheduled follow-up. Baseline characteristics of these 
Table 1 Baseline characteristics of patients.

\begin{tabular}{|c|c|}
\hline & $\begin{array}{l}\text { Number (\%) } \\
\text { or mean (S.D.) }\end{array}$ \\
\hline Gender (male/female) & $30(81 \%) / 7(19 \%)$ \\
\hline Age (years) & $45(15.4)$ \\
\hline Systolic blood pressure (mmHg) & $105.5(16.2)$ \\
\hline Diastolic blood pressure (mmHg) & $68.0(9.1)$ \\
\hline Resting heart rate (bpm) & $81(13.3)$ \\
\hline Diuretics & $33(89.2 \%)$ \\
\hline$\beta$-Blockers & $30(81.1 \%)$ \\
\hline $\begin{array}{l}\text { Angiotensin-converting enzyme } \\
\text { inhibitors }\end{array}$ & $26(70.3 \%)$ \\
\hline Angiotensin receptor type- 1 blockers & $3(8.1 \%)$ \\
\hline Amiodarone & $14(37.8 \%)$ \\
\hline LV ejection fraction (\%) & $26.2(8.3)$ \\
\hline LV end-diastolic diameter (mm) & $68.3(10.5)$ \\
\hline$V O_{2 \max }(\mathrm{ml} / \mathrm{min}$ per $\mathrm{kg})$ & $17.4(5.8)$ \\
\hline TSH (mIU/l) & $3.1(3.0)$ \\
\hline Total $\mathrm{T}_{3}(\mathrm{ng} / \mathrm{ml})$ & $0.84(0.2)$ \\
\hline Total $\mathrm{T}_{4}(\mu \mathrm{g} / \mathrm{dl})$ & $8.1(1.5)$ \\
\hline Hct (\%) & $41.6(4.6)$ \\
\hline Creatinine $(\mathrm{mg} / \mathrm{dl})$ & $1.24(0.56)$ \\
\hline
\end{tabular}

patients are shown in Table 1. The investigation conformed to the principles outlined in the Declaration of Helsinki. Post-ischemic dilated cardiomyopathy was diagnosed by coronary artery disease found on coronary angiography or by documented myocardial infarction. Non-ischemic dilated cardiomyopathy was diagnosed based on the absence of coronary artery disease on coronary angiography. Coronary angiography was performed at the time of diagnosis of the disease. Patients with clinical evidence of sepsis, cachexia, other severe systemic disease or primary thyroid disorder were not included in this study. All patients had standard laboratory tests $\left(\mathrm{T}_{3}\right.$, $\mathrm{T}_{4}$, thyrotropin (TSH), hematocrit (Hct), creatinine, etc.) and subjected to echo-cardiographic evaluation and cardiopulmonary exercise testing. The laboratory tests and echo-cardiographic evaluation were initially performed during the first hospital admission, while cardiopulmonary exercise testing was performed within 2 weeks thereafter. In a subgroup of patients $(n=8)$, we performed sequential measurements of $\mathrm{T}_{3}, \mathrm{~T}_{4}$, and TSH within 2 weeks to check for variation in thyroid hormone values. $T_{3}, T_{4}$, and TSH values within the same patient were highly reproducible.

\section{Thyroid hormone measurements}

Total $\mathrm{T}_{3}$ and $\mathrm{T}_{4}$, and TSH were measured in plasma. The normal values of thyroid hormones and TSH were ranged from 0.6 to $1.6 \mathrm{ng} / \mathrm{ml}$ for total $\mathrm{T}_{3}, 58$ to $156 \mathrm{nmol} / \mathrm{l}(4.5$ to $12 \mu \mathrm{g} / \mathrm{dl}$ ) for total $\mathrm{T}_{4}$, and 0.3 to $3.8 \mathrm{mIU} / \mathrm{l}$ for TSH.

\section{Echocardiographic study}

Transthoracic echocardiography recordings were taken with General Electric Vivid 7 system using a $2-4 \mathrm{MHz}$ probe. Images at parasternal long-axis, short-axis, and four-chamber view were obtained. Left ventricular end-diastolic diameter, left ventricular endsystolic diameter, fractional shortening, and left ventricular EF (LVEF) were measured according to the guidelines set by the American Society of Echocardiography.

\section{Cardiopulmonary exercise testing}

Patients performed a cardiopulmonary exercise stress test to evaluate their exercise capacity by measuring peak oxygen consumption $\left(\mathrm{VO}_{2 \max }, \mathrm{ml} / \mathrm{kg}\right.$ per min). Exercise testing with respiratory gas exchange measurements was performed using the MedGraphics CPX/MAX (Medical Graphics Corp., St Paul, MN, USA) measuring system, while patients exercised on a treadmill according to the Dargie protocol (11). Peak oxygen consumption during exercise was recorded as the mean value during the last minute of exercise.

\section{Statistical analysis}

All data are expressed as mean (s.D.). Potential correlations between continuous variables were evaluated by the Pearson product-moment (Pearson $r$ ) or by the Spearman rank correlation coefficient (Spearman $r$ ), as appropriate. Independent sample $t$-test or nonparametric Mann-Whitney $U$-test (for continuous variables) and $\chi^{2}$-test (for dichotomized variables) were used to assess differences in parameters between groups. A $P$ value of 0.05 was considered statistically significant. Continuous variables (age, systolic and diastolic blood pressure, $\mathrm{T}_{3}, \mathrm{~T}_{4}, \mathrm{TSH}, \mathrm{LVEF}$, and Hct) were entered in the linear multiple logistic regression model using a stepwise method to identify potential independent determinants of $\mathrm{VO}_{2 \max }$.

\section{Results}

\section{Left ventricular performance and thyroid hormone levels in plasma}

$\mathrm{T}_{3}$ levels in plasma were significantly correlated to the functional indices measured in the study. In fact, $\mathrm{T}_{3}$ levels were strongly correlated with $V_{2}$ max $(r=0.78$, $P=2 \times 10^{-8}$ ), while no significant correlations were found between $\mathrm{VO}_{2 \max }$ and $\mathrm{T}_{4}$ or TSH (Fig. 1).

A weaker but significant correlation between $\mathrm{T}_{3}$ and LVEF\% $(r=0.56, P=0.0004)$, systolic (SBP, $r=0.43$, $P=0.009)$ and diastolic (DBP, $r=0.46, P=0.004$ ) blood pressure was also observed (Fig. 2). No significant correlations were found between $\mathrm{LVEF} \%$ or SBP or DBP and $\mathrm{T}_{4}$ or TSH.

In a multivariate linear logistic regression analysis that included $\mathrm{T}_{3}, \mathrm{~T}_{4}, \mathrm{TSH}$, age, $\mathrm{LVEF} \%$, SBP, DBP, and Hct as possible predictors of $V_{2}$ max values, only total $\mathrm{T}_{3}$ and $\mathrm{LVEF} \%$ were found to be associated with $V \mathrm{O}_{2 \max }$. 
A

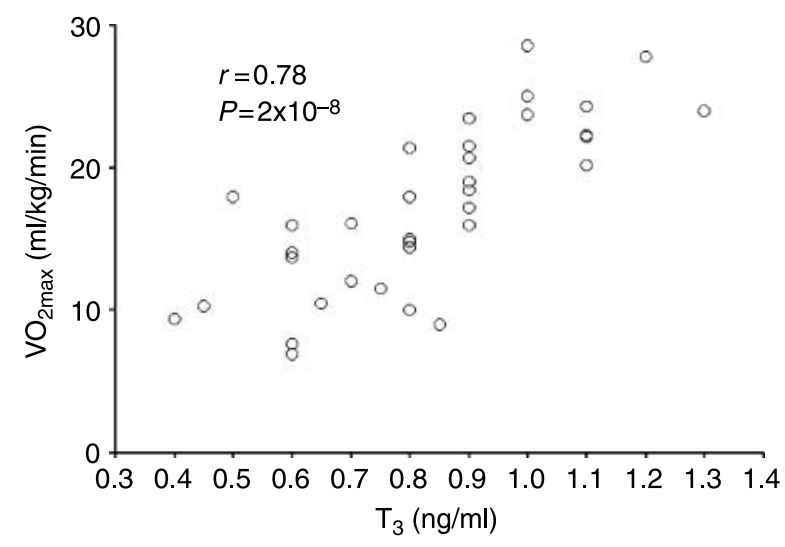

B

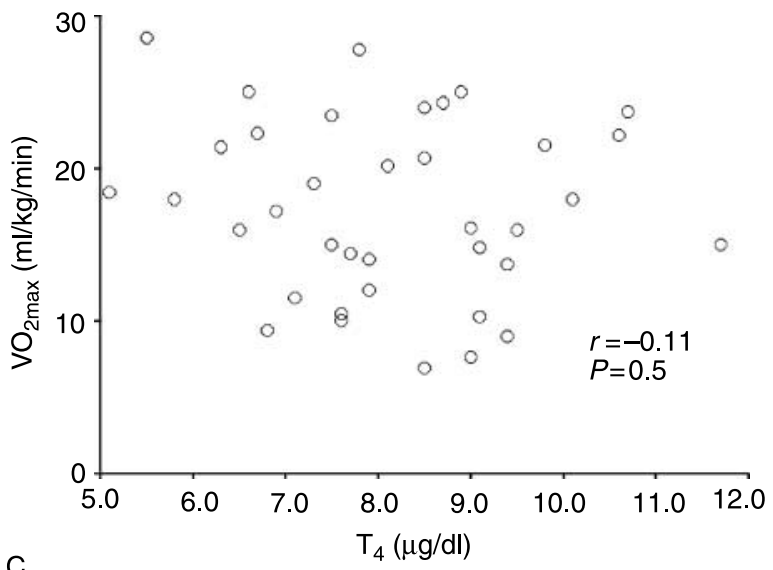

C

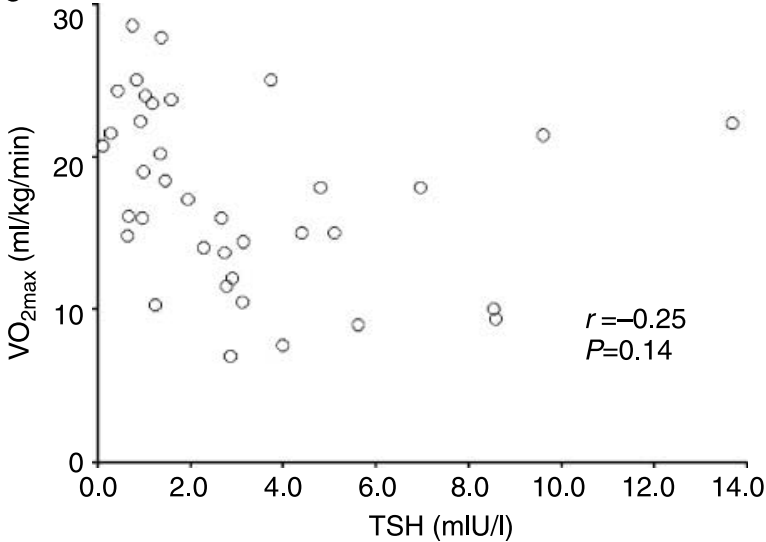

Figure 1 Scatterplots showing correlation of $\mathrm{T}_{3}(\mathrm{~A}), \mathrm{T}_{4}(\mathrm{~B})$, and TSH (C) with maximal oxygen consumption $\left(\mathrm{VO}_{2 \max }\right)$ in patients with dilated cardiomyopathy.

Furthermore, total $\mathrm{T}_{3}$ was the strongest independent determinant of $\mathrm{VO}_{2 \max }$ (Table 2).

\section{Amiodarone and thyroid hormone levels in plasma and left ventricular performance}

Patients with amiodarone treatment had a small but non-significant decrease in $\mathrm{T}_{3}$ and a trend towards an
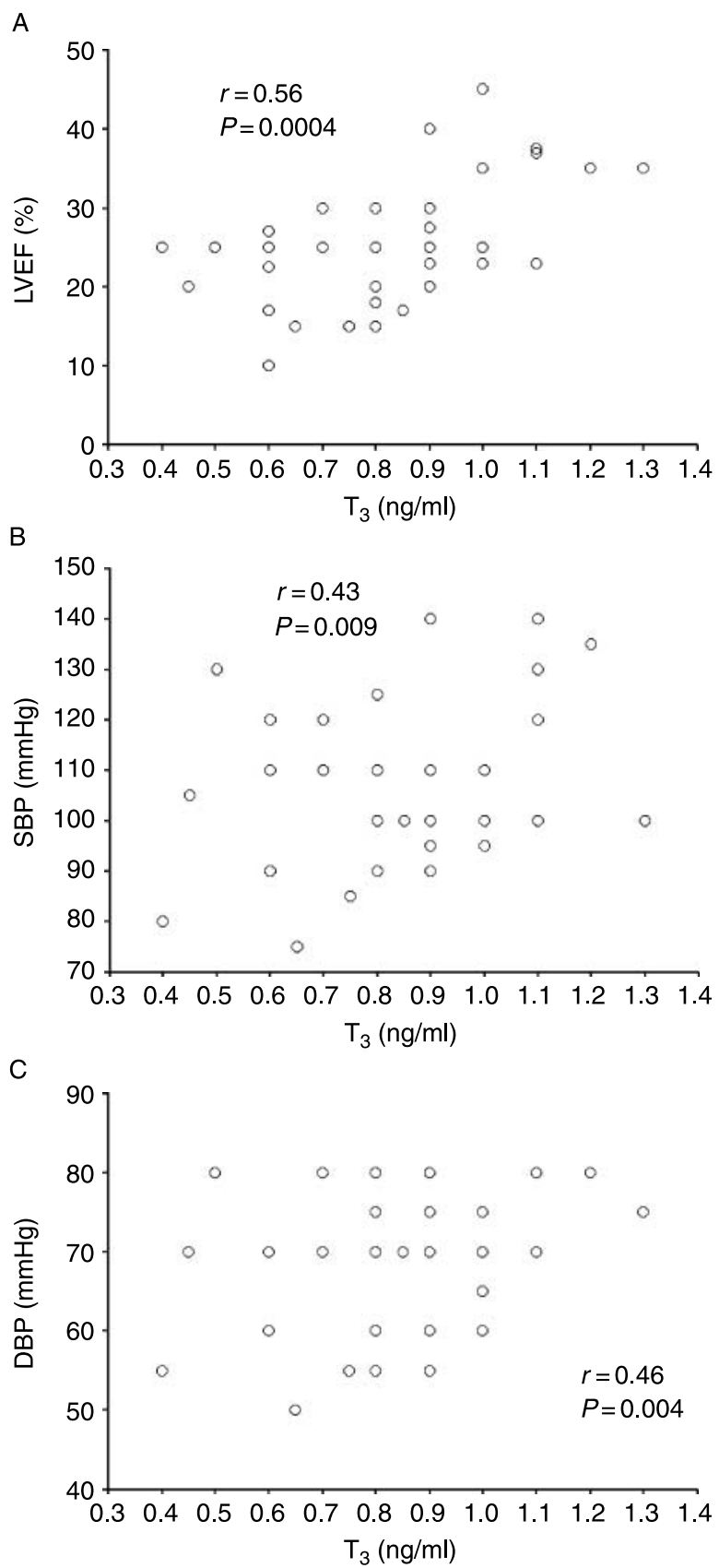

Figure 2 Scatterplots showing correlation of LVEF\% (A), SBP (B), and DBP $(C)$ with $T_{3}$ in patients with dilated cardiomyopathy.

increase in $\mathrm{T}_{4}$. In addition, TSH was found to be significantly increased in patients receiving amiodarone (Table 3). However, $V \mathrm{O}_{2 \max }, \mathrm{LVEF} \%$, SBP, and DBP were not different between patients with and without amiodarone treatment (Table 3). These results are consistent with previous reports (12).

Since amiodarone treatment could have influenced the correlation of thyroid hormone values with left ventricular performance, we performed a separate analysis in heart failure patients not treated with amiodarone. $\mathrm{T}_{3}$ 
Table 2 Tri-iodothyronine $\left(T_{3}\right)$ and left ventricular ejection fraction $\%$ (LVEF\%) are independent predictors of $V_{O_{2 m a x}}$ in patients with dilated cardiomyopathy (multivariate linear regression analysis).

\begin{tabular}{lrll}
\hline & \multicolumn{1}{c}{$\boldsymbol{r}$} & \multicolumn{1}{c}{$\boldsymbol{r}^{\mathbf{2}}$} & \multicolumn{1}{c}{$\boldsymbol{P}$ value } \\
\hline $\begin{array}{l}\text { Independent variables } \\
\mathrm{T}_{3}\end{array}$ & & & \\
LVEF\% & 0.78 & 0.61 & 0.000005 \\
Excluded variables & 0.84 & 0.70 & 0.006 \\
DBP & & & \\
SBP & 0.11 & - & 0.71 \\
Age & 0.14 & - & 0.77 \\
Hct & 0.02 & - & 0.94 \\
$\mathrm{~T}_{4}$ & 0.09 & - & 0.80 \\
TSH & -0.14 & - & 0.94 \\
& -0.22 & - & 0.96 \\
\hline
\end{tabular}

levels were also strongly correlated with $V_{2 \max }(r=0.84$, $P=10^{-6}$ ), while no significant correlation was found between $V_{2}$ max and $\mathrm{T}_{4}$ (Fig. 3). Interestingly, in this subgroup of patients, TSH showed a significant negative correlation with $V_{2} \mathrm{O}_{\max }$ values $(r=-0.62, P=0.002$; Fig. 3). A significant correlation between $\mathrm{T}_{3}$ and $\mathrm{LVEF} \%$ $(r=0.53, P=0.009)$, SBP $(r=0.46, P=0.03)$ and DBP $(r=0.49, P=0.02)$ was also observed.

\section{Discussion}

There is accumulating experimental evidence showing that changes in thyroid hormone and/or thyroid hormone receptors (TRs) can occur in cardiac hypertrophy and myocardial infarction, and this seems to be of physiological relevance (7-10). More importantly, after myocardial infarction in rats, changes in myosin isoform expression in the myocardium are evident, corresponding to exacerbation of cardiac dysfunction. This response is thought to be due to the TR $\alpha 1$ aporeceptor repressive activity (10). Interestingly, this type of TR appears to be overexpressed in human myocardium in patients with dilated cardiomyopathy (13). Thus, it is likely that thyroid hormone signaling may have a critical role in the pathophysiology of heart failure.

Table 3 Left ventricular performance and thyroid hormone levels in patients with and without amiodarone treatment. Data are presented as mean (S.D.).

\begin{tabular}{|c|c|c|c|}
\hline & $\begin{array}{c}\text { Patients } \\
\text { without } \\
\text { amiodarone } \\
\text { treatment }\end{array}$ & $\begin{array}{c}\text { Patients } \\
\text { with } \\
\text { amiodarone } \\
\text { treatment }\end{array}$ & $P$ value \\
\hline$N$ & 23 & 14 & \\
\hline Total $\mathrm{T}_{3}(\mathrm{ng} / \mathrm{ml})$ & $0.86(0.2)$ & $0.80(0.21)$ & 0.46 \\
\hline Total $\mathrm{T}_{4}(\mu \mathrm{g} / \mathrm{dl})$ & $7.7(1.1)$ & $8.8(1.8)$ & 0.06 \\
\hline TSH (mlÜ/l) & $2.1(1.9)$ & $4.8(3.8)$ & 0.02 \\
\hline LV ejection fraction (\%) & $28(9.0)$ & $25(6.1)$ & 0.3 \\
\hline $\mathrm{VO}_{2 \max }(\mathrm{ml} / \mathrm{min}$ per $\mathrm{kg})$ & $18.0(5.7)$ & $16.3(6.0)$ & 0.38 \\
\hline $\begin{array}{l}\text { Systolic blood pressure } \\
(\mathrm{mmHg})\end{array}$ & $105(17)$ & $106(16)$ & 0.96 \\
\hline $\begin{array}{l}\text { Diastolic blood pressure } \\
\qquad(\mathrm{mmHg})\end{array}$ & $68.0(9.5)$ & $67.8(8.7)$ & 0.95 \\
\hline
\end{tabular}
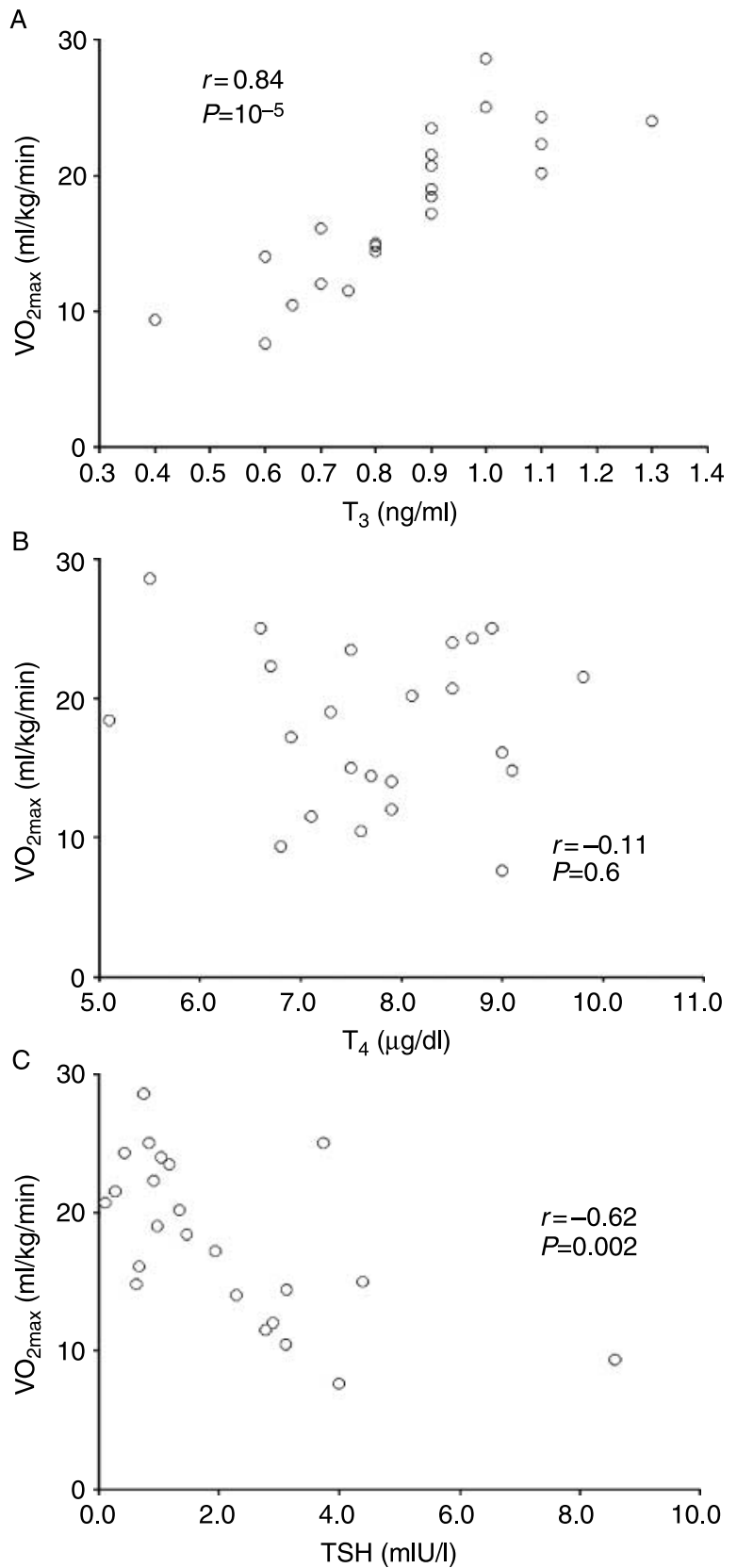

Figure 3 Scatterplots showing correlation of $T_{3}(A), T_{4}(B)$, and TSH (C) with maximal oxygen consumption $\left(\mathrm{VO}_{2 \max }\right)$ in patients with dilated cardiomyopathy without amiodarone treatment.

As a 'proof of concept', the present study shows a close correlation between changes in thyroid hormone in plasma and myocardial performance as that assessed by blood pressure measurements, left ventricular EF and peak oxygen consumption on cardio-respiratory exercise testing. In fact, total $T_{3}$ levels in plasma were significantly correlated with $\mathrm{LVEF} \%$ in accordance with previous reports (14). A weak positive correlation between $\mathrm{T}_{3}$, and systolic and diastolic blood pressure 
was also observed. It is interesting to note that lower $\mathrm{T}_{3}$ levels in the setting of heart failure were not associated with increased diastolic pressure, as has been observed in hypothyroid and subclinical hypothyroid patients $(15,16)$. This probably reflects different pathophysiological mechanisms underlying these two conditions.

The present study provides additional evidence of the importance of $\mathrm{T}_{3}$ on the cardio-respiratory exercise testing response in patients with heart failure; a strong correlation between total $\mathrm{T}_{3}$ and the peak oxygen consumption was observed and the variability in $V \mathrm{O}_{2 \text { max }}$ could be explained by almost $61 \%$ by changes in $\mathrm{T}_{3}$ values. Furthermore, multivariate analysis showed that total $\mathrm{T}_{3}$ was the strongest independent determinant of $\mathrm{VO}_{2 \max }$. At this point, it should be noted that the present study included a number of patients treated with amiodarone, which can interfere with thyroid hormone signaling and potentially influence our results. However, a persistent correlation between triiodothyronine and myocardial performance was still observed in the absence of amiodarone treatment. Furthermore, no significant differences in $\mathrm{T}_{3}$ levels and functional indices were found between the amiodarone treated and non-treated patients. It is interesting to note that abnormal thyroid hormone function has previously been shown to correlate to NYHA classification regardless of amiodarone treatment (3). Taken together, these data appear to be of important clinical significance. Peak oxygen consumption provides a precise estimate of aerobic capacity and is considered to be a sensitive index to assess functional status in patients with heart failure (17). Moreover, peak oxygen consumption independently predicts mortality $(18,19)$. In fact, the freedom from death or urgent cardiac transplantation was found to be only $48 \%$ in 1 year in patients with peak oxygen consumption of $<14 \mathrm{ml} / \mathrm{min}$ per $\mathrm{kg}$. In contrast, patients without significant comorbidities and peak oxygen consumption $>14 \mathrm{ml} / \mathrm{min}$ per $\mathrm{kg}$ had 1 -year survival of $94 \%(20)$.

\section{Limitations of the study}

The present study is the first to provide evidence on the importance of total $\mathrm{T}_{3}$ on the cardio-respiratory testing response in patients with heart failure. Although the study has not included a large number of patients, this may be the basis for further investigation in this new field of research. Furthermore, it should be noted that free fractions of thyroid hormones in plasma were not measured. We measured only the total $\mathrm{T}_{3}$, which in previous experimental and clinical studies has been mostly associated with increased mortality and impaired cardiac function $(5,10)$.

In conclusion, changes in thyroid hormone are closely correlated to myocardial functional status in patients with heart failure. These data are in accordance with experimental observations that strongly support a potential role of thyroid hormone in the pathophysiology of heart failure. This may be of physiological and therapeutic relevance.

\section{Acknowledgements}

We thank our students N Tsinarakis and E Livadarou for their valuable assistance.

\section{References}

1 Klein I \& Ojamaa K. Thyroid hormone and the cardiovascular system. New England Journal of Medicine 2001344 501-509.

2 Pantos C, Malliopoulou V, Varonos DD \& Cokkinos DV. Thyroid hormone and phenotypes of cardioprotection. Basic Research in Cardiology 200499 101-120.

3 Ascheim DD \& Hryniewicz K. Thyroid hormone metabolism in patients with congestive heart failure: the low triiodothyronine state. Thyroid $2002 \mathbf{1 2}$ 511-515.

4 Manowitz NR, Mayor GH, Klepper MJ \& DeGroot LJ. Subclinical hypothyroidism and euthyroid sick syndrome in patients with moderate-to-severe congestive heart failure. American Journal of Therapeutics 19963 797-801.

5 Pingitore A, Landi P, Taddei MC, Ripoli A, L'Abbate A \& Iervasi G. Triiodothyronine levels for risk stratification of patients with chronic heart failure. American Journal of Medicine 2005118 132-136.

6 Schmidt-Ott UM \& Ascheim DD. Thyroid hormone and heart failure. Current Heart Failure Reports 20063 114-119.

7 Belke DD, Gloss B, Swanson EA \& Dillmann WH. AAV-mediated expression of thyroid hormone receptor isoforms $\alpha 1$ and $\beta 1$ improves contractile function in pressure overload-induced cardiac hypertrophy. Endocrinology 2007148 2870-2877.

8 Kinugawa K, Yonekura K, Ribeiro RC, Eto Y, Aoyagi T, Baxter JD, Camacho SA, Bristow MR, Long CS \& Simpson PC. Regulation of thyroid hormone receptor isoforms in physiological and pathological cardiac hypertrophy. Circulation Research 200189 591-598.

9 Pantos C, Mourouzis I, Saranteas T, Paizis I, Xinaris C, Malliopoulou V \& Cokkinos DV. Thyroid hormone receptors $\alpha 1$ and $\beta 1$ are downregulated in the post-infarcted rat heart: consequences on the response to ischaemia-reperfusion. Basic Research in Cardiology 2005100 422-432.

10 Pantos C, Mourouzis I, Xinaris C, Kokkinos AD, Markakis K, Dimopoulos A, Panagiotou M, Saranteas T, Kostopanagiotou G \& Cokkinos DV. Time-dependent changes in the expression of thyroid hormone receptor $\alpha 1$ in the myocardium after acute myocardial infarction: possible implications in cardiac remodelling. European Journal of Endocrinology 2007156 415-424.

11 Riley M, Northridge DB, Henderson E, Stanford CF, Nicholls DP \& Dargie HJ. The use of an exponential protocol for bicycle and treadmill exercise testing in patients with chronic cardiac failure. European Heart Journal 199213 1363-1367.

12 Amico JA, Richardson V, Alpert B \& Klein I. Clinical and chemical assessment of thyroid function during therapy with amiodarone. Archives of Internal Medicine 1984144 487-490.

13 d'Amati G, di Gioia CR, Mentuccia D, Pistilli D, ProiettiPannunzi L, Miraldi F, Gallo P \& Celi FS. Increased expression of thyroid hormone receptor isoforms in end-stage human congestive heart failure. Journal of Clinical Endocrinology and Metabolism 2001 86 2080-2084.

14 Pingitore A, Iervasi G, Barison A, Prontera C, Pratali L, Emdin M, Giannessi D \& Neglia D. Early activation of an altered thyroid 
hormone profile in asymptomatic or mildly symptomatic idiopathic left ventricular dysfunction. Journal of Cardiac Failure 2006 12 520-526.

15 Luboshitzky R, Aviv A, Herer P \& Lavie L. Risk factors for cardiovascular disease in women with subclinical hypothyroidism. Thyroid $200212421-425$.

16 Biondi B \& Klein I. Hypothyroidism as a risk factor for cardiovascular disease. Endocrine 200424 1-14.

17 Weber KT, Kinasewitz GT, Janicki JS \& Fishman AP. Oxygen utilization and ventilation during exercise in patients with chronic cardiac failure. Circulation 198265 1213-1223.

18 Cohn JN, Johnson GR, Shabetai R, Loeb H, Tristani F, Rector T, Smith R \& Fletcher R. Ejection fraction, peak exercise oxygen consumption, cardiothoracic ratio, ventricular arrhythmias, and plasma norepinephrine as determinants of prognosis in heart failure. The V-HeFT VA Cooperative Studies Group. Circulation 199387 VI5-VI16.

19 O'neill JO, Young JB, Pothier CE \& Lauer MS. Peak oxygen consumption as a predictor of death in patients with heart failure receiving beta-blockers. Circulation $20051112313-2318$.

20 Mancini DM, Eisen H, Kussmaul W, Mull R, Edmunds LH \& Wilson JR. Value of peak exercise oxygen consumption for optimal timing of cardiac transplantation in ambulatory patients with heart failure. Circulation 199183 778-786.

Received 14 May 2007

Accepted 9 July 2007 